\title{
“ON-WATER” RING OPENING REACTIONS: A REVIEW
}

\author{
Niharika Verma \\ Shri Jai Narain Misra Post Graduate (KKC) College, Lucknow, Uttar Pradesh, India \\ *Corresponding author: niharikaverma15@gmail.com
}

\begin{abstract}
The replacement of current organic chemical processes with more environmentally benign alternatives is an important goal from an ecological point of view. The study is aimed with the goal of promoting water as a solvent in organic synthesis. In recent years, extensive industrial and scholarly research has been promoted for the development of organic reactions in aqueous media. Using water as a solvent often promotes considerable rate enhancements and operational simplicity. Environmental benefits of using water are additionally highlighted in relation to the Twelve Principles of Green Chemistry.
\end{abstract}

Keywords: On-water reactions, In-water reactions, Green chemistry, Co-solvents, Epoxides, Aziridines.

\section{INTRODUCTION}

Solvents and reagents play an important role in synthetic chemistry. The selection of these two should be environmentally benign. Organic chemists usually rely upon organic solvents to perform the reactions. In nature many biological reactions proceeds in aqueous environments and these fascinating in vivo reactions should prompt organic chemists to explore the potential of water as a medium for organic reactions. Terms frequently used in the literature for reactions in aqueous medium are "in water" and "on water" [1] according to the solubility organic compound. When the solute is completely water soluble, then the reaction is termed as proceeding in "in water". Reactions of water insoluble organic compounds, taking place in aqueous suspensions are termed as "on water" reactions.

Water is most abundant, environmentally benign, inexpensive and non flammable solvent in nature [2]. Yet, its application in organic synthesis is currently limited [3]. As most organic compounds have low solubility in water, much effort has been done in the development of organic environments in the aqueous phase [4]. Thus, in many examples of "aqueous reactions" organic cosolvents are used in order to increase the solubility of organic reactants in water [5]. To increase the hydrophilicity of the reactants polar functional groups are introduced, to make the organic compounds at least partially soluble in water [6]. Mostly, organic cosolvents, such as the lower alcohols, acetone, DMF and $\mathrm{ACN}$, are used for increasing the solubility of hydrophobic solutes in water [7]. The amount of water can vary widely, from substoichiometric quantities to a large amount in which the reactants can be suspended or dissolved. Besides using cosolvent, environmentally benign catalyst can also be used. There are various examples of micellar catalysis in the presence of non-ionic surfactants, such as Triton-X and Aliquat-336 [8].

Recently, "on water" reactions have received a great deal of attention because of their high efficiency and environment friendly synthetic protocols [9]. A considerable rate acceleration is often observed when "on water" organic synthesis is proceeded. This can be explained on the basis of hydrophobic effects [10], where non- polar reactant molecules are forced together in the rate determining transition state. The rate of "on water" acceleration varies between different reaction classes and organic moieties. Even if the rate acceleration is negligible and the use of water is only as the supporting medium, then also it has other advantages including ease of product isolation and above all, safety, due to its high heat capacity [11] in case of exothermic reactions. Last but not least "on water" reactions also help in retaining the aspect of "green chemistry".

The field of aqueous organic synthesis has been frequently and broadly reviewed. The objective of this study is to review "on water" ring opening reactions under various conditions. 


\section{RING OPENING REACTIONS}

Many nucleophilic ring opening reactions of reactants having hetero atoms showed considerable rate acceleration when preceded "on water". Efficient "on water" nucleophilic ring opening reaction of epoxides and aziridines 1 promoted by tributylphosphine to corresponding anti bifunctional products $\mathbf{2} \mathbf{a}$ and $\mathbf{2} \mathbf{b}$ was reported with moderate to excellent yield of $61-98 \%$ (Scheme 1) [12].

$\mathrm{X}=\mathrm{O}, \mathrm{N}$ - Tosyl

$\mathrm{NuH}=\mathrm{ArOH}, \mathrm{RSH}, \mathrm{RNH}_{2}$

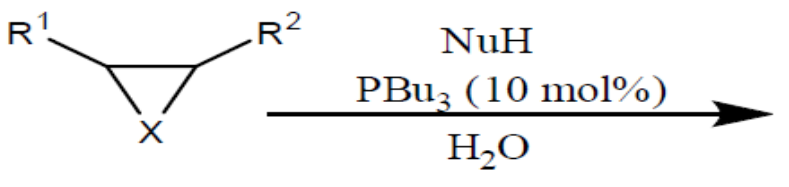

1

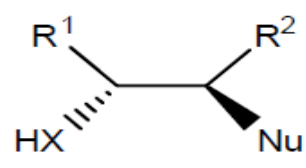

$2 \mathbf{a}$

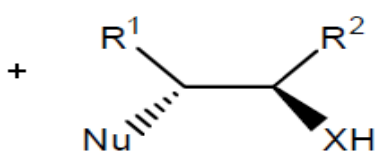

2b

\section{Scheme 1}

"On water" highly regioselective ring opening of oxiranes 3 with phenoxides in the presence of catalytic amount of $\beta$ - cyclodextrin $(\beta$-CD) to yield $\beta$ - hydroxy ethers 4 (Scheme 2) was reported by Surendra et al. [13].

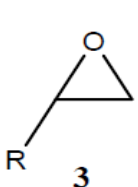

3

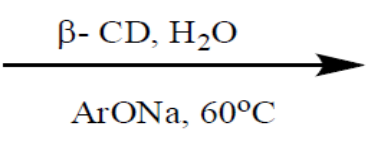

Scheme 2

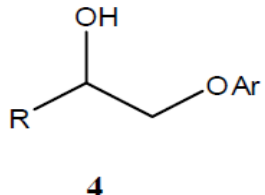

4
Table 1: Ring opening of 5

\begin{tabular}{ccc}
\hline Solvent & $\mathrm{t}(\mathrm{h})$ & Yield of $\mathbf{7}(\%)$ \\
\hline Toluene & 120 & $<10$ \\
EtOH & 72 & 89 \\
Neat & 60 & 76 \\
$\mathrm{H}_{2} \mathrm{O}$ & 12 & 88 \\
\hline
\end{tabular}

Saidi and Azizi studied "on water" aminolysis of epoxides 8 by aliphatic and aromatic amines (Scheme 4) [15]. $\alpha$ - amino alcohol 9 was synthesized with higher selectivity and significant yield.

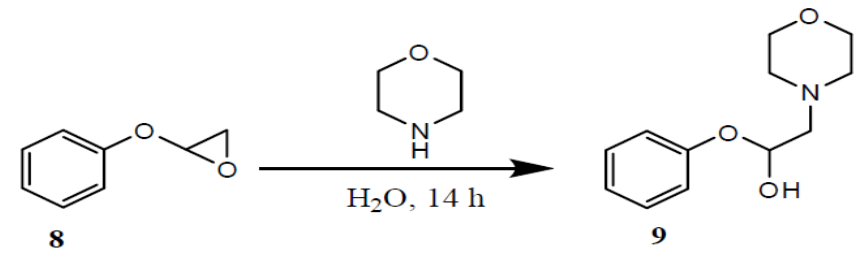

\section{Scheme 4}

Kobyashi et al studied "on water" ring opening of meso epoxides $\mathbf{1 0}$ with aromatic amine $\mathbf{1 1}$ in presence of chiral bipyridine ligand (1.2 $\mathrm{mol} \%)$ and $\mathrm{Sc}$ $\left(\mathrm{OSO}_{3} \mathrm{C}_{12} \mathrm{H}_{25}\right)_{3}(1 \mathrm{~mol} \%)$. The reaction provided higher yield of $\beta$-amino alcohol 12 with significant enantioselectivities (Scheme 5) [16].

Scheme 3

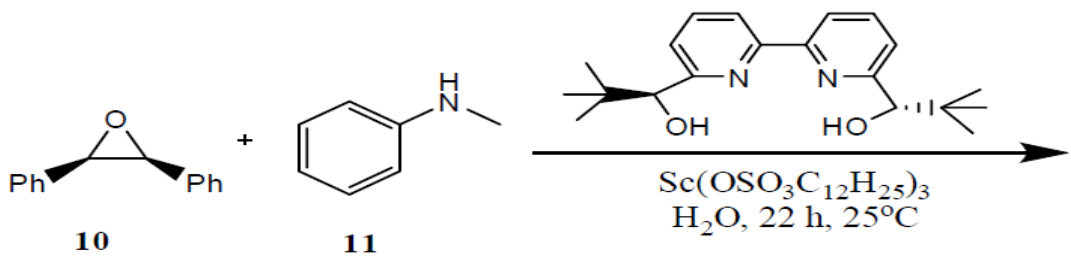

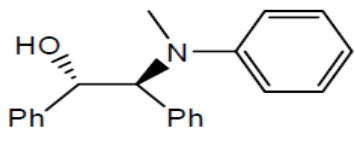

12

\section{Scheme 5}


The nucleophilic ring opening of epoxides 13 from amines 14 and carbon disulfide 15 gave $\beta$ dithiocarbamate derivatives 16 (Scheme 6) [17]. The yield of 16 was highly benefited by "on water" conditions.

Earlier Saidi and Azizi synthesized "on water" $\alpha$ - amino alcohols 9. Later on they also synthesized $\beta$ - amino alcohols by highly efficient "on water" ring opening reactions of epoxides $\mathbf{1 7}$ with deactivated aromatic amines catalysed by heteropoly acids (Scheme 7) [18]. The product $\beta$ - amino alcohols 18 were produced in moderate to excellent yield.

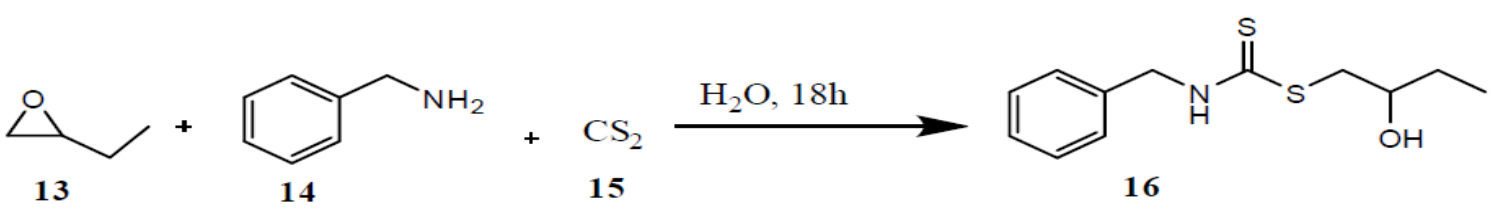

Scheme 6

$\mathrm{DO}_{\mathrm{H}} \frac{\mathrm{ArNH}_{2}, \mathrm{H}_{2} \mathrm{O}(8 \mathrm{ml}), 24 \mathrm{~h}, \mathrm{rt}}{\mathrm{H}_{3} \mathrm{PW}_{12} \mathrm{O}_{40}(0.35 \mathrm{~mol} \%)} \rightarrow$

17

Scheme 7

Nucleophilic ring opening of unactivated aziridines, as cyclohexyl imine 19 may also benefit from the "on water" environment. Cyclohexyl imine showed excellent yield (90\%) of 1,2 amino azide 20 on reaction with sodium azide and also gave high yield (95\%) of 1,2 amino hydrazine 21 with hydrazine "on water" at ambient temperature (Scheme 8) [19].

Vilotijevic and Jamison reported the ring opening of diepoxide 22 and triepoxide 24 (Scheme 9) [20]. Ring opening of these epoxides are generally disfavoured in organic solvents. But they are readily converted to their respective fused tetrahydropyranes 23 and 25 respectively under "on water" environment. The reaction was preceded with higher yield (50 to 60\%) and absolute stereocontrol.

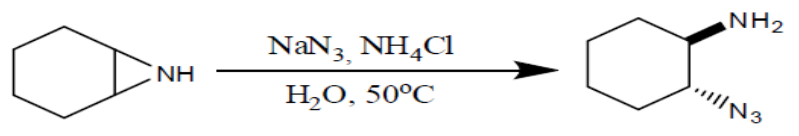

19

20

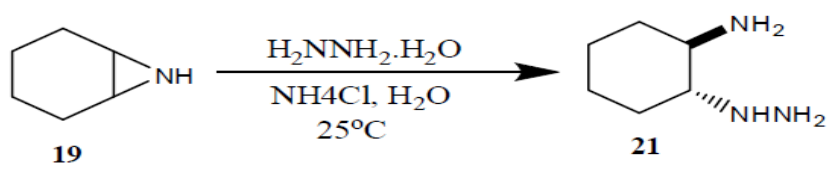

\section{Scheme 8}

Regioselective nucleophilic ring opening of epoxides using water as a solvent to yield $\beta$ - amino alcohols 27 $(\mathbf{a}+\mathbf{b})$ was reported by Sreedhar et al (Scheme 10) [21]. The product was synthesised under ambient conditions using amines $\mathbf{2 6}$ as a nucleophile and silica nanoparticles as a catalyst.
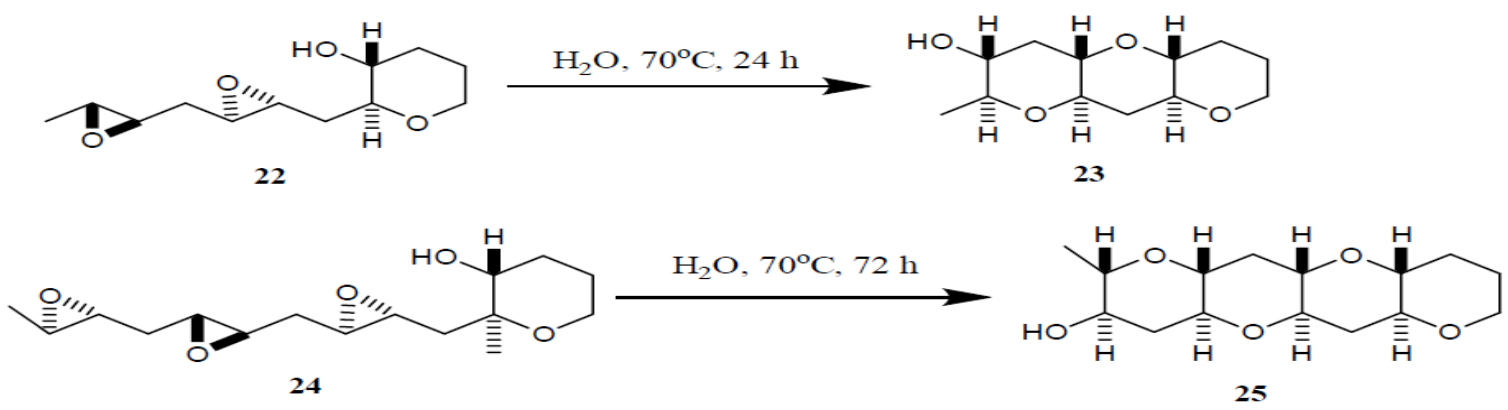

Scheme 9
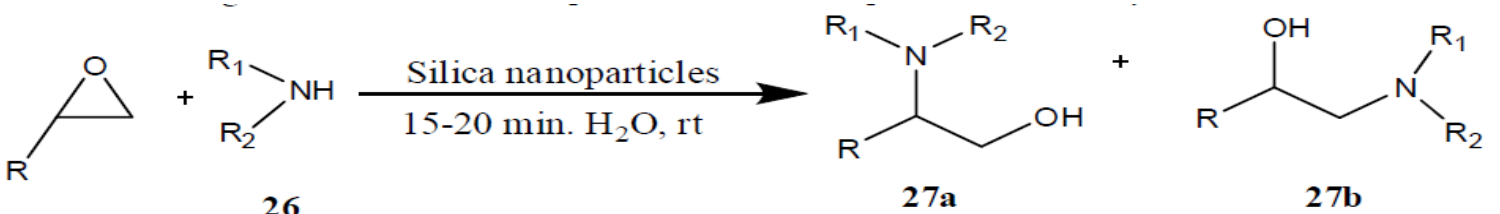

\section{Scheme 10}


Efficient conversion of epoxides with thiourea 28 to thiiranes 29 and with aromatic or aliphatic amines 30 to $\beta$-amino alcohols 31 in presence of catalytic amount of aluminium tris (dodecyl sulphate) trihydrate
$\mathrm{Al}(\mathrm{DS})_{3} \cdot 3 \mathrm{H}_{2} \mathrm{O}$ were reported by Firouzabadi et al (Scheme 11) [22]. The reaction was proceeded "on water" at room temperature to give excellent yield with high chemo and regioselectivity.
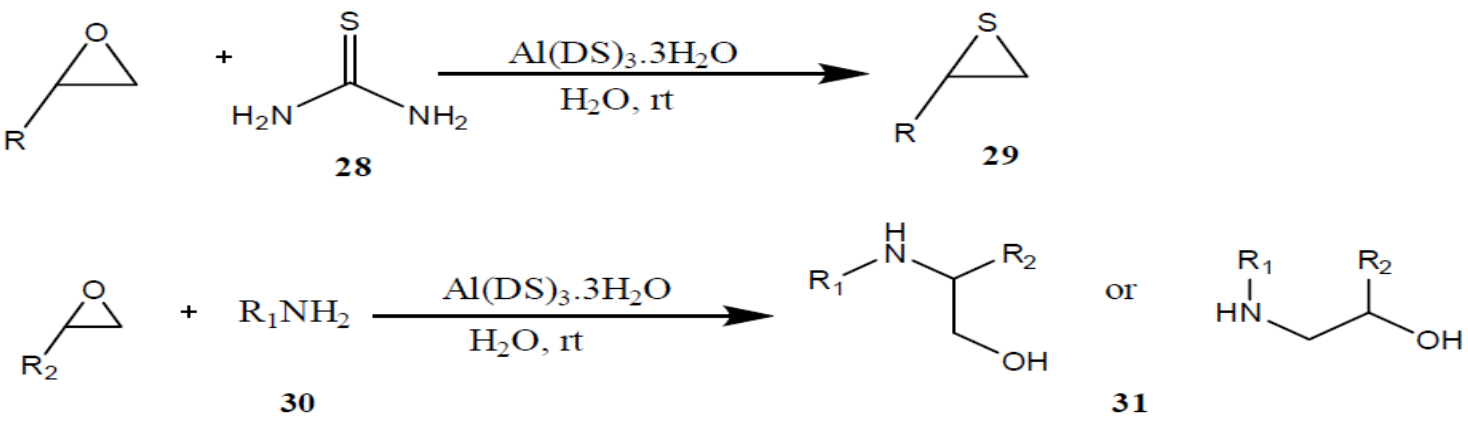

$\mathrm{R}_{1}=$ aromatic or aliphatic

\section{Scheme 11}

Effective hydrolysis of epoxides and aziridines was reported in hot water at the temperature of $60^{\circ} \mathrm{C}$ or $100^{\circ} \mathrm{C}$ leading to ring opening (Scheme 12) [23]. It was proposed that during hydrolysis water acts as modest catalyst and a solvent. The reported yield of the hydrolysed product 32 was 77-99\%.

$\mathrm{X}=\mathrm{O}, \mathrm{NR}_{3}$

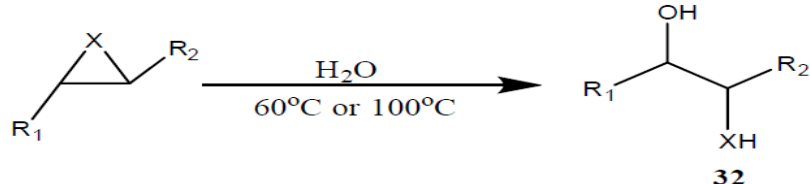

Scheme 12

"On water" ring opening of styrene oxide 33 with diethylamine gives excellent yield of two isomers of amino alcohols 34 (a+b) (Scheme 13) [24] in comparison to other solvents (Table 2).
Plazinski et al [25] describes the water catalyzed mechanism of the ring opening reaction of glucose. Results based on advanced computational studies indicate that the water molecules deprotonate the anomeric hydroxyl group and the subsequent proton transfer to the ring oxygen atom, which triggers the ring cleavage.

Table 2: Nucleophilic ring opening of 33 in various solvents

\begin{tabular}{ccc}
\hline Solvent & Yield of $\mathbf{3 4 a}+\mathbf{3 4 \mathbf { b } ( \% )}$ & $\mathbf{3 4 \mathbf { a } / 3 4 \mathbf { b }}$ \\
\hline $\mathrm{Neat}$ & $-*$ & \\
$\mathrm{CH}_{2} \mathrm{Cl}_{2}$ & $-*$ & \\
$\mathrm{CH}_{3} \mathrm{CN}$ & $-*$ & \\
$\mathrm{Hexane}$ & $-*$ & \\
Ethanol & 50 & $24: 76$ \\
Diethyl ether & $-*$ & \\
$\mathrm{H}_{2} \mathrm{O}$ & 92 & $5: 55$ \\
\hline
\end{tabular}

*No product observed

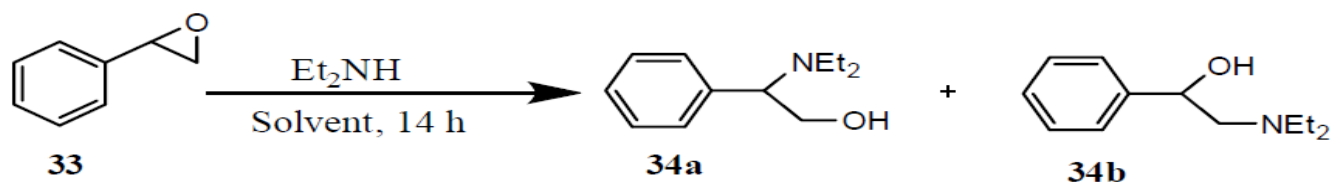

\section{Scheme 13}

Ahsan et al [26] reported that the water plays a $\mathrm{CO}^{-}$ catalytic role in epoxide ring opening reactions in Aspartate Proteases, potential targets for various diseases. QM/MM molecular dynamics show that the reaction proceeds via two step mechanism with the formation of oxyanion intermediate. Formed intermediate is stabilised by the water molecules in the protein active site. Low barrier hydrogen bonds of 
water molecules with the epoxide ring, reduce the intrinsic reaction barrier while structurally remains unperturbed. Later on Ahsan et al [27] attempt to unravel the electronic basis of the co-catalytic role of water in the epoxide ring opening reaction.

\section{CONCLUSION}

Efficient reactions in aqueous organic chemistry do not require soluble reactants, as had been thought. A newly developed "on water" protocol is characterised by short reaction times, and the products are easy to isolate. This review gives us a glimpse of the stimulating role of water in several epoxide ring opening reactions. "On water" ring opening reactions proceeds with highest chemical efficiency via green pathway. Reproducible, safe procedures illustrate utility of aqueous media and the practical simplicity afforded.

\section{Conflict of interest}

None declared

\section{REFERENCES}

1. Hayashi Y. Angew. Chem. Int. Ed., 2006; 45:8103.

2. Grieco PA. Blake Academic and Professional, London, 1998.

3. Grieco PA. Springer New York, 1997.

4. Blokzijl JB, Engberts FN. J.Am.Chem.Soc., 1992; 144:5440.

5. Lindstrom UM. Chem.Rev., 2002; 102:2751.

6. Itami K, Yoshida J. I.Chem.Rec., 2002; 2:213.

7. Satoshi M, Mitsuo K. Chem.Rev., 2009; 109:711.

8. Lipshutz BH, Chung DW, Rich B. Org.Lett., 2008; 10:3793.

9. Price BK, Tour JM. J.Am.Chem.Soc., 2006; 128:12899.
10. Breslow RJ. Phys.Org.Chem., 2006; 19:813.

11. Narayan S, Jhon M, Finn MG, Fokin VV, Kolb C, Sharpless KB. Angew. Chem. Int. Ed., 2005; 44:3275.

12. Fan RH, Hou XL. J. Org. Chem., 2003; 68(3):726730.

13. Surendra K, Krishnaveni NS, Nageswar YVD, Rao KR. J. Org. Chem., 2003; 68(12):4994-4995.

14. Narayan S, Muldoon J, Finn MG, Fokin VV, Kolb HC, Sharpless KB. Angew. Chem., Int. Ed., 2005; 44:3275.

15. Azizi N, Saidi MR. Org. Lett., 2005; 7:3649.

16. Azoulay SP, Manabe K, Kobayashi S. Org. Lett., 2005; 7:4593.

17. Saidi MR, Ziyaei-Halimjani A. Can. J. Chem., 2006; $84: 1515$.

18. Azizi N, Saidi MR. Tetrahedron., 2007; 63(4):888891.

19. Narayan S, Fokin VV, Sharpless KB. Lindstrom UM.. Ed.; Blackwell:Oxford, U.K., 2007; 350-365.

20. Vilotijevic I, Jamison TF. Science., 2007; 317:1189.

21. Sreedhar B, Radhika P, Neelima B, Hebalkar N. J. Molecular catalysis A:Chemical., 2007; 272:159-163.

22. Firouzabadi H, Iranpoor N, Khoshnood A. J. Molecular catalysis A:Chemical., 2007; 274:109-115.

23. Wang Z, Cui Y, Xu Z, Qu J. J. Org. Chem., 2008; 73(6):2270-2274.

24. Chanda A, Fokin VV. Chem. Rev., 2009; 109:725748.

25. Plazinski W, Plazinski A, Drach M. Phys. Chem. Chem. Phys., 2015; 17:21622-21629.

26. Ahsan M, Senapati S. J. Phys. Chem B., 2019; 123(38):7955-7964.

27. Ahsan M, Pindi C, Senapati S. J. Mol. Graph. Model., 2021; 105:107894. 